\title{
Risk Factors and Prevalence of Hepatitis B Surface Antigen (HBsAg) among Apparently Healthy Volunteers in an Urban Setting, North- Central Nigeria
}

\author{
J. A. Ndako¹ , F. C. Onwuliri², J. M. Banda3 , O. O. Alejolowo¹, V. \\ Fajobi $^{4}$, D. O. Olapade 4
}

\author{
${ }^{1}$ Department of Biological Sciences, Microbiology Unit, Landmark University, Omuaran Nigeria \\ ${ }^{2}$ Department of Plant Science and Technology, University of Jos, Nigeria \\ ${ }^{3}$ Department of Pathology, Kaduna State University Nigeria \\ ${ }^{4}$ Department of Laboratory Services, Landmark University Medical center, Omuaran Nigeria
}

\begin{abstract}
Hepatitis B virus (HBV) infection is a serious global public health problem and responsible for most common liver infection worldwide. The infection if contracted early in life, may lead to chronic liver disease, including cirrhosis and hepatocellular carcinoma. The aim of this study was to determine Hepatitis B Surface Antigenemia (HBsAg) and risk factors of transmission among apparently healthy asymptomatic individual volunteers in Jos metropolis. In order to estimate and further evaluate prevalence rate of HBsAg in our population of study, a well-structured questionnaire was used to obtain the social and demographic information of consenting participants, while ethical approval was sought and obtained. Two hundred (200) volunteer subjects were enrolled for the study, three milliliter $(3 \mathrm{ml})$ of venous blood samples were collected aseptically by venipuncture. Sera obtained were assayed for the HBsAg using the HBsAg test strip (Acon Laboratory incorporated USA).Confirmatory tests were performed for Serum HBsAg by using a third generation enzyme linked Immunosorbent assay (HBsAg ELISA)-(Bio-Rad Laboratories, Incorporated California, USA). Overall results showed a prevalence of $45(22.5 \%)$ positivity among subjects screened. considering gender $25(12.5 \%)$ were males while $20(10.0 \%)$ were females, $(\mathrm{p}=0.020)$,Age distribution showed that subjects aged 25-29 years recorded a prevalence of $10(12.5 \%) ;(\mathrm{p}=0.001)$, this is relatively high in view of the fact that the study subjects were a apparently healthy population. Clinical risk factors showed that $2.5 \%$ of sero-positive subject had a history of blood transfusion $(\mathrm{p}=0.480)$, while $4.5 \%$ had a record of previous STD infection $(\mathrm{p}=0.423)$.Serological markers among the apparently healthy individuals screened showed; 40 (20.0\%), 29 (14.5\%), 8 (4.0\%), 20 (10.0\%) and 38 (19.0\%) for $\mathrm{HBsAg}$, Anti HBs, HBeAg, Anti HBe and Anti HBc respectively $(\mathrm{P}<0.005)$.Changes in liver enzymes among subjects that tested positive for the HBV showed that. the apparently healthy individuals recorded an abnormality of 13(28.9\%) respectively, $[\mathrm{P}=0.0144 ;(\mathrm{P}<0.005)]$. This study however confirms the presence of Hepatitis B surface antigenemia among apparently healthy individuals in our study locations. This calls for mass immunization and public health education on the dangers of this infectious agent in the population.
\end{abstract}

Keywords: Hepatitis B surface antigen (HBsAg), apparently healthy volunteers, Serological Markers.

\subsection{Introduction}

Hepatitis B virus (HBV) has been described as a major public health concern, occurring endemically, in all areas of the world (Maddrey et al., 2000). Chronic hepatitis is characterized by the presence of HBsAg in the blood for a period above six months. Although chronic hepatitis B carriers may remain asymptomatic as the infection remains inactive, this could actually progress to liver fibrosis, cirrhosis and hepatocellular carcinoma (HCC). Yang et al., reported that cirrhosis is present in majority of hepatitis B patients and chronic viral hepatitis is said to play a major role in activating liver fibrosis (Budhu, 2006 and Yang, 2011).HCC is reported to be the "third leading cause of cancer-related death in the world", with about $78 \%$ of HCC being attributed to

This article is published under the terms of the Creative Commons Attribution License 4.0 Author(s) retain the copyright of this article. Publication rights with Alkhaer Publications.

Published at: http://www.ijsciences.com/pub/issue/2016-03/

DOI: 10.18483/ijSci.958; Online ISSN: 2305-3925; Print ISSN: 2410-4477 
viral hepatitis of which HBV is inclusive (Yang, 2011).

Based on the prevalence of HBV chronic carriers amongst adults in the general population, Countries are classified as having low endemicity $(<2 \%)$, intermediate endemicity $(2 \%-5 \%)$, or high endemicity (> 5\%) of infection (Hall, 1994). Hepatitis B is highly endemic in developing nations with large population such as South East Asia,China, sub-Saharan Africa and the Amazon basin (Sharma et al., 2005), with at least $8.0 \%$ of the population assuming HBV chronic carrier status.(Alter, 2003). In Eastern and Southern Europe, the Middle East, Japan, and part of South America, mixed pattern of transmission exist, including transmission among infants, early childhood and adult transmission (Lok, 2005).

The endemicity of HBV is low in most developed countries, such as North America, Northern and Western Europe and Australia. In these regions, HBV infects $5.0-7.0 \%$ of the population, and only $0.5-2.0 \%$ of the population become chronic carriers. In these areas, most HBV infections occurs in adolescents and young adults in relatively well defined high-risk groups, comprising injection drug users, homosexual males, health-care workers, blood transfusion or hemodialysis patients (WHO, 1998). In Africa, hepatitis B virus infection is the most common cause of liver disease which is the third most common cause of death in medical wards with 15-60\% seropositivity for HBsAg in normal population (Bojuwoye, 1997; Ugwuja and Ugwu, 2010).

HBV infections constitute a major public health concern in Nigeria while several reports have established the endemicity of HBV by the presence of HBsAg in different groups of population studied from different parts of the country,(Olubuyide,1997). The evaluation of the data on the prevalence of the HBsAg provided an idea on its prevalent rate in the community (Bhattacharya et al., 2007; Afsar et al., 2010). HBV are blood borne pathogens that can be transmitted through blood transfusion and could pose a huge problem in areas where mechanisms of ensuring blood safety are uncertain (Umolu et al., 2005).

A study carried out on one hundred (100) healthy blood donors in Benin City showed a prevalence of $11.0 \%$, compared to the report from a study conducted in Central Hospital, Warri where a prevalence of $12.0 \%$ was recorded. Similarly, a prevalence of $4.4 \%$ was reported in another study carried out in Lagos among healthy pregnant women. The prevalence of HBV varies between $2 \%$ in developed countries where the prevalence is low to about $8 \%$ in developing countries where infection is endemic with sex, age and socio-economic status as important risk factors for infection (Odusanya et al., 2005; Alikor and Erhabor, 2007)

HBV is found in highest concentrations in the blood, and lower concentrations in saliva, semen, vaginal secretions, and wound exudates. The virus can remain viable for $>7$ days on environmental surfaces at room temperature (CDC, 2008). Sexual activity, especially heterosexual, and injection-drug use account for the majority of HBV transmission in lowprevalence areas (Seeger et al., 2000) while perinatal transmission account for the majority of the transmission in high prevalence areas (Harry et al., 1994).However, HCC might be prevented by early detection and therapy (Xuan et al.,2007).

The prevalence of $\mathrm{HBV}$ infection also varies markedly from one region of the world to another. Racial differences between populations, cultural and economic differences in developing countries like Nigeria are factors considered responsible for the differences. The global burden of Hepatitis B remains enormous, due largely to lack of universal HBV vaccination (Alexander and Kowdley, 2006).The prevalence observed from previous studies demands for a routine use of Serological markers for HBV screening in blood banks and antennal clinics. These tests are obligatory for transfusion safety and may give an idea about the seropositivity rates of a specific region (Afsar et al., 2010).

\subsection{Materials and Methods}

3.1 Study area: The study was carried out in some parts of Plateau State. This comprises of Jos metropolis comprising parts of Jos South and Jos North, Local Government areas. The selection of these communities was as a result of preliminary investigations conducted among amongst families with symptoms suspected to be an indicator for the HBV.

3.2 Ethical consideration: Informed consent of each participant was obtained prior to testing. Ethical approval for this research work was sought and obtained from relevant authorities.

3.3 Study Population: Subjects studied include; Two Hundred (200) apparently Healthy Individuals. The study included subjects of all sex, aged 3 to 60 years.

Inclusion and Exclusion criteria: Subjects who gave informed consent and are asymptomatic by routine screening, were included in the study, subjects who had once been vaccinated with the required three doses of the vaccine and those who declined to offer consent were excluded from the study. 
3.4 Collection and processing of specimens: Three milllilitre $(3 \mathrm{ml})$ of blood samples were collected aseptically by venipuncture using Syringe and needle. Each blood sample was transferred from the syringe into a carefully labelled plastic microtitre tube containing ethylene diamine tetraacetic acid (EDTA) and stored in the refrigerator at $4^{\circ} \mathrm{C}$.Each resultant supernatant (Plasma) was carefully decanted into a new labelled tube and stored at $-20^{\circ} \mathrm{C}$ until ready for use.

3.5 laboratory analysis: Assay of collected sample was carried out first by carrying out an Onthe-spot testing for HBsAg using the HBsAg test strip (Acon Laboratory incorporated USA), according to the manufacturer's instructions. Confirmatory tests were then performed with Monolisa HBsAg ULTRA assay (HBsAg ELISA test reagent)(Biorad Laboratories,USA) which is a one-step enzyme Immunoassay according to the manufacturer's instructions.

\section{Hepatitis B Surface Antigen (HBsAg) Detection:HBsAg test strip manufactured by Acon laboratory incorporated USA was used for the preliminary screening. The HBsAg one step hepatitis $B$ surface antigen test strip is a rapid chromatographic immune assay for the qualitative detection of hepatitis B surface antigen in serum or plasma. The test was carried out and interpreted according to the manufacturer's instructions.}

Confirmation by ELISA:HBsAg ELISA test reagent manufactured by Biorad Laboratories was used for the confirmatory screening.Monolisa HBsAg ULTRA assay is a one-step enzyme Immunoassay technique of the "Sandwich" type for the detection of the surface antigen of the Hepatitis B virus (HBsAg) in the serum or plasma.

Table 1: Distributions of Apparently Healthy Subjects Screened Based On Sex and Age
Screening using the 5-panel test kits for Serological markers: HBV-5 panel test for the qualitative assessment of the markers of hepatitis B virus infection in human serum, plasma and whole blood. The HBV Panel Test is an Immunochromatographic assay method to quickly detect five major markers of $\mathrm{HBV}$ infections, HBsAg, Anti-HBs (HBsAb), Anti-HBc (HBcAb), $\mathrm{HBeAg}$ and Anti-HBe (HBeAb) in human blood specimens.

Liver Enzyme determination among seropositive individuals: All the HBsAg positive samples were assayed for alanine aminotransferase (ALT).

\section{Results}

From the tables below, out of the Two- Hundred (200) subjects screened a prevalence of $45(22.5 \%)$ positivity was recorded, considering gender 25 $(12.5 \%)$ were males while $20(10.0 \%)$ were females. Individuals aged 25-29 years recorded a prevalence of $5.0 \%$ compared to the $3.5 \%$ prevalent recorded among subjects aged 30-34 years, (Table 1). Risk factors among Apparently Healthy subjects showed that $10(5.0 \%)$ of subjects that tested positive had history of alcoholic consumption while $9(4.5) \%$ of the subjects screened had history of Sexually Transmitted Disease (STD), (Table 2).Furthermore, history of hepatitis infection in the family which recorded a prevalence of $3.0 \%$.(Table 3). Response to serological markers showed that the highest rate of positivity recorded with the $\mathrm{HBsAg}$ had $20 \%$ positivity, the $\mathrm{HBeAg}$ recorded $4.0 \%$ positivity, while Anti-HBs which indicates antibody to the HBsAg showed $14.5 \%$ positivity among the subjects screened. Anti-HBe positivity recorded 10.0\%.However,Anti-HBc Positivity showed a positivity of $19.0 \%$ (Table 4).The positive subjects screened, recorded an ALT abnormality of $28.9 \%$.(Table 5).

\begin{tabular}{llllll} 
Total Number & No. Pos. $(\%)$ & No. Neg. $(\%)$ & P-value & OR & 95\% C.I \\
Examined. $(\%)$ & & & & \\
\hline
\end{tabular}

Sex

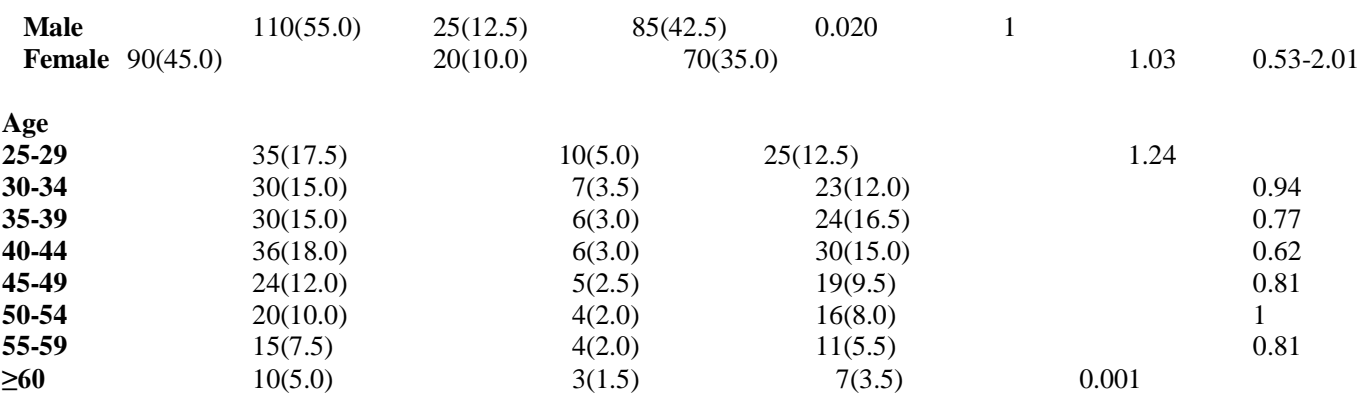


Risk Factors and Prevalence of Hepatitis B Surface Antigen (HBsAg) Among Apparently Healthy Volunteers in an Urban Setting, North-Central Nigeria

Table 2: Distributions of Apparently Healthy Subjects Screened Based on Clinical Risk Factors

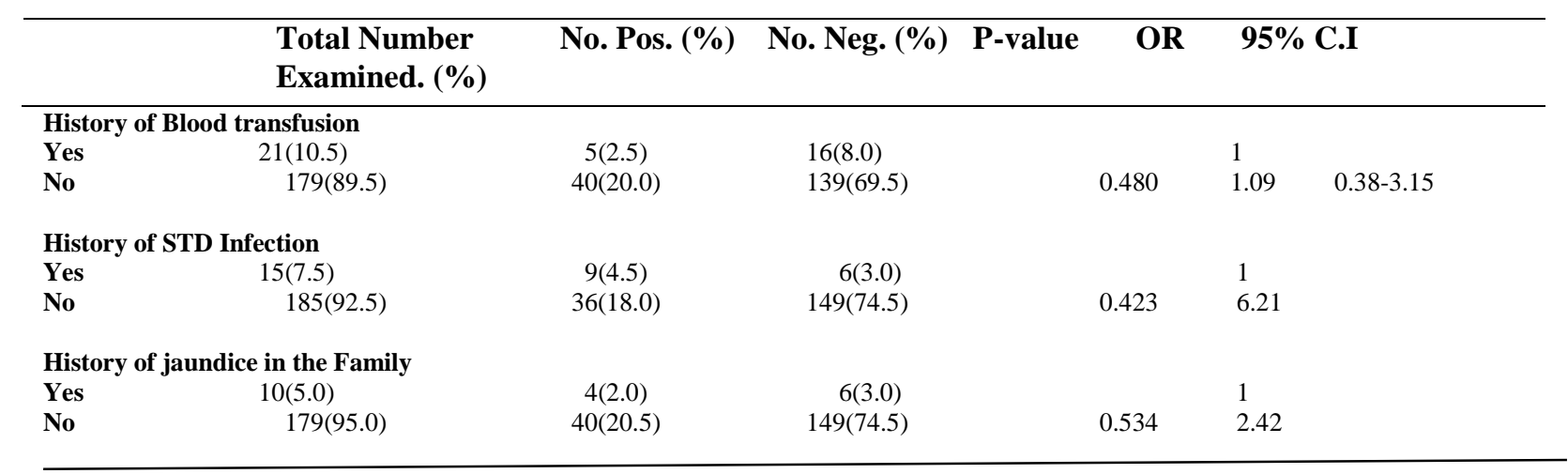

Table 3: Distributions of Apparently Healthy Subjects Screened Based on other Risk Factors

\begin{tabular}{|c|c|c|c|c|c|}
\hline $\begin{array}{l}\text { Total Number } \\
\text { Examined. }(\%)\end{array}$ & No. Pos. (\%) & No. Neg. (\%) & P-value & OR & $95 \%$ C.I \\
\hline \multicolumn{6}{|l|}{ f Hepatitis infection in the Family } \\
\hline $46(23.0)$ & $6(3.0)$ & $40(20.0)$ & & & 1 \\
\hline $154(77.0)$ & $39(19.5)$ & $115(57.5)$ & & 0.312 & 0.44 \\
\hline \multicolumn{6}{|l|}{ Infection with $\mathrm{HBV}$} \\
\hline $9(4.5)$ & $5(2.5)$ & $4(2.0)$ & & & 1 \\
\hline 191(95.5) & $40(20.0)$ & $151(74.5)$ & & 0.542 & 4.72 \\
\hline \multicolumn{6}{|l|}{ ss of HBV as an Infectious Agent } \\
\hline & & & & 0.1275 & 0.13 \\
\hline \multicolumn{6}{|l|}{ f Alcoholic Consumption } \\
\hline $30(15.0)$ & $4(2.0)$ & $6(3.0)$ & & & 1 \\
\hline $170(85.0)$ & $30(15.0)$ & $140(70.0)$ & & 0.428 & 2.33 \\
\hline
\end{tabular}

Table 4: Overall Prevalence of HBV markers among Positive subjects screened

\begin{tabular}{lllllll}
\hline & HBsAg & HBeAg & Anti- HBs & Anti- HBe & Anti- HBc & P-Value \\
\hline Positive & $40(20.0 \%)$ & $8(4.0 \%)$ & $29(14.5 \%)$ & $20(10.0 \%)$ & $38(19.0 \%)$ & $162(81.0 \%$ \\
& Negative & $160(80.0 \%)$ & $192(96.0 \%)$ & $171(85.5 \%)$ & $180(90.0 \%)$ & \\
\hline & & & & & \\
\hline
\end{tabular}

Table 5: Overall Determination Of Serum Alanine Aminotransferase (Alt) Levels On Positive Subjects Screened

\begin{tabular}{|c|c|c|c|c|}
\hline Sex & $\begin{array}{l}\text { Total Number } \\
\text { of Positive Subjects } \\
\text { Screened (\%) }\end{array}$ & $\begin{array}{l}\text { Total Number of } \\
\text { abnormal ALT } \\
\text { Level }(\%)\end{array}$ & \begin{tabular}{l}
\multicolumn{2}{l}{ Total Number of } \\
Normal \\
Level $(\%)$
\end{tabular} & P-Value \\
\hline
\end{tabular}

Males $\quad$ Females

$\begin{array}{llllll}25(55.6) & 20(44.4) & 45(100.0) & 13(28.9) & 32(71.1) & P=0.0144\end{array}$




\section{Discussion}

Screening asymptomatic people is an important instrument in disease detection, prompt diagnosis and intervention especially in silent killers like HBV. This study therefore set out to determine the seroprevalence of HBsAg in an apparently healthy population. Of the 200 subjects screened a prevalence of the $45(22.5 \%)$ positivity was recorded, considering gender $25(12.5 \%)$ were males while $20(10.0 \%)$ were females, for $\mathrm{HBsAg}$, this is relatively high in view of the fact that the study subjects apparently healthy population.

In comparison to studies from other parts of the country, the prevalence of infection reported in this study was higher than previous studies conducted in different parts of the country, such as 4.9 and $10.3 \%$ reported in Port Harcourt and Jos respectively (Ejele and Ojule, 2004; Sirisena et al, 2002),In a similar study conducted by Akani et al. (2005) among pregnant women in Port Harcourt a low prevalence of $4.3 \%$ was recorded, while a prevalence of $21.3 \%$ was recorded in a study conducted at Ibadan (Otegbayo et al, 2003) and $17.1 \%$ prevalence recorded among sex workers in Nasarawa state (Nneka, 2007). However a slightly higher prevalent rate was recorded in one of the two studies conducted in Jos,with a record of $23.9 \%$ and $15.1 \%$ prevalence (Uneke et al, 2005; Egah et al, 2007).These differences might not be unconnected with the fact that some of the studies were not from the same risk group.

Individuals aged 25-29 years recorded a prevalence of $5.0 \%$ compared to the $3.5 \%$ prevalent recorded among subjects aged 30-34 years. Chang, (2007) and Uneke et al,(2005) found that this age group comprises the sexually active group, which support the role of sexual transmission of the virus (Dawaki and Kawo 2006).However, there was no statistical significant association between the viral infection and age. Similarly there was no significant association between gender and viral infection $(\mathrm{P}>0.05)$ although the prevalence was higher (12.5\%) among the males.

It was observed from this study that more males $(12.5 \%)$ were infected with $\mathrm{HBV}$ than females $(10.0 \%)$ while more females, However Bwogi et al. (2009) in his study reported a lower prevalence of HBV in men than in female and suggested the interplay of circumcision as protective. This was not the case in this study even though it was in an area that male circumcision is mandatory.

Risk factors among Apparently Healthy subjects showed that $10(5.0 \%)$ of subjects that tested positive had history of alcoholic consumption, Alcohol remains the single most significant cause of liver disease throughout the Western world and is responsible for between 40 and $80 \%$ of cases of cirrhosis in different countries. Several studies in urban areas have reported that alcoholics have an increased prevalence of hepatitis B infection (Jacobson et al, 1992).

Similarly, not only may alcoholics have an increased risk of contracting hepatitis $\mathrm{B}$, but once infected, hepatitis B may occasionally exacerbate liver disease in these patients. Several studies have reported that alcoholic patients with advanced liver disease (cirrhosis) have a higher prevalence of hepatitis B markers than alcoholics with less severe forms of alcoholic liver disease (Jacobson et al, 1992). Hence Abuse in alcohol consumption may favor the development of HBV chronic infection because alcohol can compromise the immune system (Laskus et al, 1988).

This study showed that $9(4.5 \%)$ of the subjects screened had history of Sexually Transmitted Disease (STD).Busch (2000) and Lee et al,(2006) confirmed that sexual and prenatal HBV transmission usually results from mucous membrane exposures to infectious blood and body fluids. Saravanan et al, (2007) reported that HBsAg had been found in all body secretions and excretions. However, only blood, vaginal and menstrual fluids, and semen has been shown to be infectious.

There were no statistically significant differences with respect to contact with patient who had history of jaundice with a prevalence of $2.0 \%$. History of hepatitis $\mathrm{B}$ infection in the family recorded a prevalence of 3.0\%, Kuhns (2004) reported that HBV infection may also be transmitted between household contacts and between sexual partners, either homosexual or heterosexual, and in toddler-aged children in groups with high $\mathrm{HBsAg}$ carrier rate.

The findings of this study indicated 5\% of HBV positive cases were alcoholic consumers while $4 \%$ are due to STD. However, Lee et al,(2006) asserts that the major risk factor for both HBV infections is parenteral exposure. HBV is stable on environmental surfaces for at least 7 days, and indirect inoculation of HBV can occur via inanimate objects like toothbrushes, baby bottles, and toys, razors, eating utensils, hospital equipment and other objects, by contact with mucous membranes or open skin breaks (Pan and Zhang, 1996). In this study there were no statistically significant differences with respect to method of nail trimming, method of ear piercing, shaving and subjects with history of blood transfusion.

Serologic testing for the diagnosis of hepatitis B virus (HBV) infection involves measurement of a panel of distinct HBV-specific antigens and host antibodies that react to these antigens (Mahoney,1999). In 
general, the panel of responses can determine whether a patient is susceptible to infection, immune as a result of resolved infection, immune as a result of vaccination, acutely infected, or chronically infected.

Patients who develop chronic (persistent) HBV infection have a serologic response in the acute phase of HBV infection that is similar to patients who subsequently resolve the HBV infection. With chronic (persistent) HBV infection, HBsAg and anti$\mathrm{HBc}$ (IgG antibodies) generally persist for life, (Weinbaum, 2008). The diagnosis of acute HBV infection is established by a characteristic serologic profile. During acute infection, the appearance of Virologic markers and host antibody responses develop in a typical pattern (Mast et al., 2006). The first serologic marker to appear is hepatitis B surface antigen (HBsAg), which can initially be detected in serum from 1 to 12 weeks (average, 30 to 60 days) after infection.

From this study the highest rate of positivity recorded involved the HBsAg with $20 \%$ among the apparently healthy subjects, According to (Lee, 2010). The presence of HBsAg for longer than 6 months after acute infection indicates chronic infection. The detection of HBsAg and absence of $\operatorname{IgM}$ anti-HBc in a single serum specimen also generally indicates chronic HBV infection. The HBeAg recorded in this study showed $4.0 \%$.According to Yang et al, 2002 the presence of $\mathrm{HBeAg}$ in serum indicate active viral replication. Zhang et al,(2011) in his studies recorded $1.6 \% \mathrm{HBe} \mathrm{Ag}$ positivity among young adults while the rate of positivity decreased with age due to the spontaneous seroconversion to the Antibody against the $\mathrm{HBeAg}$.

In the study conducted by Tsai et al,(2008), Liver function tests are used to determine if the liver has been damaged or its function impaired. Elevations of certain liver tests in relation to others aids in that determination ALT result showed abnormality in $28.0 \%$ of the subjects screened. ALT levels have been correlated positively with liver inflammation, while patients with persistently normal ALT levels had significantly lower liver damage compared with patients with either intermittent of persistently elevated ALT Levels (Zhang et al. 2011).Therefore measurement of aminotransferase levels by serial observations and analysis remain the most common and convenient way to identify liver inflammation in patients particularly with chronic HBV infection.

Conclusion: Prevention is the only safeguard against spread of Hepatitis B infection, through avoiding practices that increase the risk of exposure to infection. Hepatitis B vaccine must be given to high risk groups especially the sexually active groups in the population. Similarly, Health care workers coming in contact with blood and other body Fluids should also be meant to undergo full vaccine regimen against this infectious agent. Professional and public health education and implementation of infection control practices in all health facilities should be followed up and given prompt attention so as to control the spread of Hepatitis B virus in the population.

\section{References}

1) Ado, A., Alhassan, S., Chonoko, U.G and Samaila, A.U.( 2010). Seroprevalence of Hepatitis B Surface Antigen (HBsAg) among Blood donors attending Ahmadu Bello University Teaching Hospital (ABUTH), Zaria, Nigeria Bayero Journal of Pure and Applied Sciences. 3(1):20-22

2) Akani, C.I., Ojule., A.C., Opurum H.C. and Ejilemele, A.A. (2005). Sero-prevalence of hepatitis B surface antigen (HBsAg) in pregnant women in Port Harcourt, Nigeria.Nigerian Postgraduate Medical Journal, 12(4):266270.

3) Alter, M.J.(2003) Epidemiology and Prevention of Hepatitis B. Journal of Virology, 23

4) (1): 39-46

5) Alexander, J., Kowdley, K.V.(2006). Epidemiology of Hepatitis B- Clinical Implications. Research on Gastroenterology, 8:13

6) Alikor, E.A and Erhabor, O.N. ( 2007) . Seroprevalence of hepatitis B surface antigenaemia in children in a tertiary health institution in the Niger delta of Nigeria. Nigerian Journal of Medicine 16(3): 250-251.

7) Bhattacharya, P., Chandra, P.K., Data, S.,Banerjee, A., Chakraborty, S., Rajendran, K., Basu, S.K., Bhattacharya, S.K and Chakravarty, R. (2007). Significant increase in $\mathrm{HBV}, \mathrm{HCV}$, HIV and syphilis infections among blood donors in West Bengal, Eastern India 2004-2005:Exploratory screening reveals high frequency of occult HBV infection. World Journal of Gastroenterology;13(27):3730-3733.

8) Bhatti, F.A., Ullah, Z., Salawat, N., Ayub, M. and Ghani, P. (2007). Anti-Hepatitis B core antigen testing, viral markers and Occult hepatitis B virus infection in Pakistani blood donors: implications for transfusion practice. Journal of Transfusion Science, 47(1):74-79.

9) Bojuwoye, B.J. (1997) . The burden of viral hepatitis in Africa. West African Journal of Medicine, 16(4): 198-203

10) Busch, M.P. (2000). HIV; HBC and HCV new development related to transfusion safety. Vox Sanguinis, 78:253-256

11) Budhu, A and Wang, X.W (2006). The role of cytokines in hepatocellular carcinoma. Journal Leukoc. Biol. 80: 11971213.

12) Bwogi, J., Braka, F. and Makumbi, I. (2009).Hepatitis B infection is highly endemic in Uganda: Findings from a National Serosurvey. African Journal of Health Sciences. 9: 98-108.

13) CDC. (2008). Surveillance for acute viral hepatitis----United States, 2006. In: CDC Surveillance Summaries, March 21, 2008. MMWR 2008;57 (No. SS-2).

14) Chang, M.H. (2007). Hepatitis B virus infection foetal, Neonatal Medicine 12: 160-167.

15) Dawaki, S.S. and Kawo, A.H. (2006). Seroprevalence of Hepatitis B surface antigen (HBsAg) in pregnant women attending an urban maternity hospital in Kano, Nigeria. Nigerian Journal of Microbiolgy;20: 705-709.

16) Ejele, O.A. and Ojule, A.C. (2004). The Prevalence of Hepatitis B Surface Antigen (HBsAg) among prospective blood donors and patients in Port Harcourt, Nigeria. Nigerian Journal of Medicine; 13:336-338 (s)

17) Egah, D.Z., Banwat, E.B., Audu, E.S. and Iya, D,Mandong, B.M., Anele, A.A.and Gomwalk, N.E.(2007). Hepatitis B surface antigen, Hepatitis C and HIV antibodies in a low-risk blood donor group, Nigeria. East Medit Health Journal 13(4):961-6.

18) Hall, A.J.( 1994). Control of hepatitis by children 
vaccination. Reviews in Medical Microbiology. 1;5(2):12330.

19) Harry, T.O., Bajani, M.D. and Moses, A.E.(1994). Hepatitis $\mathrm{B}$ virus infection among blood donors and pregnant women in Maiduguri, Nigeria. East African Medical Journal, 70:596-597

20) Jacobson JM, Worner TM, Sacks HS, Lieber CS 1992. Human immunodeficiency virus and hepatitis B virus infections in a New York City alcoholic population. J Stud Alcohol 53: 76-79.

21) Kuhns, M.C., Kleinman, S.H., McNamara, A.L. and Busch, M.P. (2004). Lack of correlation between HBsAg and HBV DNA levels in blood donors. Transfusion, 44:1332-1339.

22) Lawal OA, Bakarey AS, Uche LN, Udeze AO, Okonko IO.( 2009). HBV infection among intending blood donors who incidentally tested positive to HIV antibody in two blood banks in Ibadan, Nigeria. World Applied Science Journal.7(10):1269-1274.

23) Laskus, T., Lupa, E., Szczutowska, E.and Babiuch, L.(1988). Prevalence of hepatitis B virus markers among polish urban alcoholics. Infection, 16: 354-357.

24) Lee, C., Gong, Y., Brok,J., Boxall, E. and Gluud, C. (2006) . Effect of hepatitis B immunisation in newborn infants of mothers positive for hepatitis B surface antigen: systematic review and meta-analysis. BMJ 332: 328-336.

25) Lee, H. (2010). Public health policy for management of hepatitis B infection: historical review of recommendations for immunisation. Public Health Nursing; 27: (2) 148-157.

26) Lok, A. (2005). Hepatitis D Virus Infection and Liver Transplantation. Journal of Virology, 2005, 24:112-114.

27) Maddrey, W.C. (2000). Hepatitis B: an important public health issue. Journal of Medical Virology. 61:362-366

28) Mast, E.E., Margolis, H.S., Fiore, A.E., Brink, E.W., Goldstein, S.T., Wang, S.A., Moyer, L.A, Bell, B.P. and Alter, M.J. (2005). A comprehensive immunization strategy to eliminate transmission of hepatitis B virus infection in the United States. MMWR;54:1-32.

29) Mahoney, F.J.(1999). Update on diagnosis, management, and prevention of hepatitis B virus infection. Clinical Microbiology. Review, 12:351-66.

30) Nneka, O. (2007). Seroprevalence of Hepatitis B virus infection in commercial sex workers in Keffi, Nigeria. B.Sc. Dissertation, Nasarawa State University pp. 1-18.

31) Odusanya, O.O., Alufohai, F.E., Meurice, F.P.,Wellens, R., Weil, J and Ahonkhai, V.I. (2005). Prevalence of hepatitis B surface antigen in vaccinated children and controls in rural Nigeria. International J. of Infect. Dis., 9(3): 139-143.

32) Oladele, O.O, Adesina, T.B., Omolola, Z.T, and Sunday, T.S. ( 2013). Prevalence of HBsAg and HIVamong blood donors in Osogbo, Osun State, Nigeria. International Research Journal of Medicine and Medical Sciences. Vol.1(3):68-71.

33) Otegbayo, J.A., Fasola, F.A. and Abja, A.(2003). Prevalence of hepatitis B surface antigens, risk factors for viral acquisition and serum transaminase among blood donors in Ibadan, Nigeria. Tropical Gastroenterology, 24(4); 196-197.

34) Olubuyide, I.O., Ola,S.O., Aliyu, B., Dosumu, O.O. and Arotiba, J.T. (1997). Hepatitis B and C in Doctors in Nigeria. Nigerian Quarterly Journal of Medicine. 90:417-422.
35) Pan, C.Q. and Zhang, J.X. (2005). Natural history and clinical consequences of hepatitis B virus infection. International Journal of Medical Science, 2:36-40.

36) Sharma, R., Sharma, C.L and Khajuria, R. (2004). The knowledge, attitude and practices regarding HBV infection of married women in the reproductive Age group living in cantonment Area Sunjawan Jammu. Journal of Med. Educ. Res. 6:127-130.

37) Saravanan, S., Velu, V. and Kumarasamy, N.(2007). Co infection of Hepatitis B and hepatitis C virus in HIV-infected patients in south India Academic Press Ltd., 569-574.

38) Seeger, C. and Mason, W.S.(2000).Hepatitis B virus biology. Microbiology and Molecular Biology Reviews, 64:51-68.

39) Sirisena, N.D., Njoku, M.O., Idoko, J.A., Isamade, E.,Barau, C., Jelpe, D., Zamani, A. and Otawa, S. (2002).Carriage rate of HBsAg in an urban community in Jos, Plateau State Nigeria. Journal of Nig.Postgrad. Med.; 9: 7-10.

40) Tsai, N. C., P. S. Holck, L. L. Wong, and A. A. Ricalde. (2008). Seroepidemiology of hepatitis B virus infection: Analysis of mass screening in Hawaii. Hepatology International 2(4):478-485.

41) Ugwuja, E. and Ugwu N. (2010). Seroprevalence of Hepatitis B Surface Antigen and Liver Function Tests among Adolescents in Abakaliki, South Eastern Nigeria. The Internet Journal of Tropical Medicine, 6(2).

42) Umolu, P.I., Okoror, L.E. and Orhue, P. (2005). Human immunodeficiency virus (HIV) Seropositivity and hepatitis B surface antigenemia (HBsAg) among blood donors in Benin City, Edo state,Nigeria. African Health Sciences; 5(1): 5558.

43) Uneke, C.J., Ogbu,P.U.I, Anyanwu,G.I, Njoku, M.O. and Idoko, J.H.( 2005). Prevalence of hepatitis B surface antigen among blood donors and HIV-infected patients in Jos, Nigeria. Memórias do Instituto Oswaldo Cruz Rio de Janerio. 100(1):13-16.

44) Weinbaum, C.M., Mast, E.E. and Ward, J.W. (2009). Recommendations for identification and public health management of persons with chronic hepatitis B virus infection. Hepatology.49:35-44.

45) World Health Organization (WHO). (1998).Hepatitis B Immunization, WHO Position-Weekly Epidemiological Record, 73:329-330.

46) Xuan,S.Y.,Xin,Y.N.,Chen,N.,Shi,G.Y.,Guan,H.S.,Li,Y. (2007). Significance of $\mathrm{HBsAg}$ and $\mathrm{HCV}$ expression in Hepatocellular Carcinoma and pericarcinomatous tissues. World journal of Gastrenology 28:1870-1874.

47) Yang, J.D, Kim, W.R., Coelho, R., Mettler,T. and J.T. (2011) . Cirrhosis is present in most patients with hepatitis B and hepatocellular carcinoma. Clinical Gastroenterol Hepatology 9: 64-70.

48) Yang, H.I., Lu,S.N. and Liaw, Y.F.(2002) Taiwan Community-Based Cancer Screening Project Group. Hepatitis B e antigen and the risk of hepatocellular carcinoma. N Engl J Med.;347:168-174.

49) Zheng, Y., Lu, Y., Ye, Q., Xia, Y., Zhou, Y., Yao, Q. and Wei S.(2011). Should chronic hepatitis B mothers' breastfeed? A meta-analysis. BMC Public Health.11:502. 